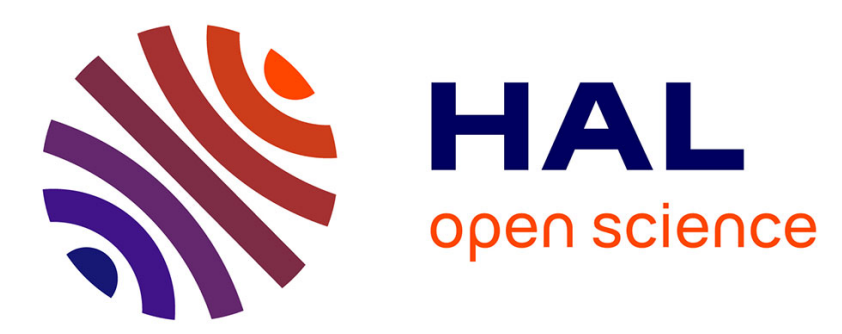

\title{
Characteristics of motor unit recruitment in boys and men at maximal and submaximal force levels
}

Emeric Chalchat, Enzo Piponnier, Bastien Bontemps, Valérie Julian, Olivia Bocock, Martine Duclos, Sébastien Ratel, Vincent Martin

\section{- To cite this version:}

Emeric Chalchat, Enzo Piponnier, Bastien Bontemps, Valérie Julian, Olivia Bocock, et al.. Characteristics of motor unit recruitment in boys and men at maximal and submaximal force levels. Experimental Brain Research, 2019, 10.1007/s00221-019-05508-z . hal-02065716

\section{HAL Id: hal-02065716 \\ https://hal.uca.fr/hal-02065716}

Submitted on 25 Mar 2019

HAL is a multi-disciplinary open access archive for the deposit and dissemination of scientific research documents, whether they are published or not. The documents may come from teaching and research institutions in France or abroad, or from public or private research centers.
L'archive ouverte pluridisciplinaire HAL, est destinée au dépôt et à la diffusion de documents scientifiques de niveau recherche, publiés ou non, émanant des établissements d'enseignement et de recherche français ou étrangers, des laboratoires publics ou privés. 


\title{
Characteristics of motor unit recruitment in boys and men at maximal and submaximal force levels
}

\author{
Emeric Chalchat ${ }^{1} \cdot$ Enzo Piponnier ${ }^{1} \cdot$ Bastien Bontemps $^{1} \cdot$ Valérie Julian $^{2} \cdot$ Olivia Bocock $^{2} \cdot$ Martine Duclos $^{2}$. \\ Sébastien Ratel ${ }^{1} \cdot$ Vincent Martin $^{1}$ (D)
}

Received: 22 October 2018 / Accepted: 4 March 2019

\begin{abstract}
The aim of this study was to compare voluntary activation (VA) and motor units (MU) recruitment patterns between boys and men at different contraction levels of the knee extensor muscles. We hypothesized that boys and men would display similar VA and MU recruitment patterns at low submaximal force levels, but that boys would display a lower utilization of their higher-threshold MU and a lower VA at near-maximal and maximal force levels than men. 11 prepubertal boys and 13 men were tested at the optimal knee angle. Next, VA was assessed using the twitch interpolation technique during maximal (MVC) and submaximal isometric voluntary contractions. Mean firing rate (MFR), recruitment threshold (RT) and motor unit action potential size $\left(\mathrm{MUAP}_{\mathrm{SIZE}}\right)$ were extracted to characterize neural strategies. No significant difference between groups was found for VA at every contraction level. Similarly, no significant difference was found for the MFR vs. RT relationship parameters between groups. For the vastus lateralis $(\mathrm{VL})$ muscle, the $\mathrm{MUAP}_{\mathrm{SIZE}}$ vs. RT relationship differed between boys and men independent of the contraction level $(p<0.05)$. Boys also displayed a different MFR vs. MUAP SIZE $_{\text {relationship on }}$ the VL muscle independent of the contraction level $(p<0.05)$. To conclude, no difference between boys and men was found for VA regardless of the contraction level investigated. Differences in motor unit recruitment parameters between boys and men seem to be explained by different muscle dimensions between groups.
\end{abstract}

Keywords Children $\cdot$ Muscle activation $\cdot$ Magnetic nerve stimulation $\cdot$ EMG decomposition

\section{Introduction}

In previous decades, knowledge in pediatric exercise physiology has significantly increased. Several studies have established that children display unique physiological characteristics and particularly, in their responses to exercise. Yet, our understanding of the influence of maturation on regulating the production of muscle force by the central nervous system remains limited. Recently, O'Brien et al. (2012) suggested that prepubertal children may not have established the full motor pathways required to drive motor neurons to their maximal capacity. Indeed, Koh and Eyre (1988) showed that the excitability of the corticospinal tract increased

\footnotetext{
$\triangle$ Vincent Martin

vincent.martin@uca.fr

1 Clermont-Auvergne University, AME2P, 63000 Clermont-Ferrand, France

2 Clermont University Hospital, Clermont-Ferrand, France
}

throughout maturation. Increases were associated with the myelinization processes and concomitant increases in nerve fiber diameter (Lauffer and Wenzel 1986; Müller et al. 1991; Geneva et al. 2002).

Additionally, Dotan et al. (2012) suggested that children could be less able to recruit or utilize their higher-threshold motor units (MU) (Type II). Children's inability to recruit higher-threshold MU than adults could be explained by differences in muscle fiber type composition between populations and/or by a differential MU recruitment (Dotan 2016). Lexell et al. (1992) reported a lower proportion of type II fibers in boys than men, which could circuitously support the assumption of the children's inability to recruit higherthreshold MU. Additionally, Dotan et al. (2012) suggested a decreased utilization of the higher-threshold MU in children by reporting differences in indirect surface electromyographic (EMG) parameters between children and adults. Indeed, some studies (Pitt et al. 2015; Long et al. 2017) reported a higher electromyographic threshold in children compared to adults. 
Due to ethical limitations, no study has directly compared MU recruitment patterns between healthy children and adults. However, an original EMG technique has been recently developed to decompose EMG signals and enable MU identification. This technique offers the advantage of examining MU sizes and firing rates in relation to recruitment threshold from the surface of the skin (De Luca et al. 2006; Pope et al. 2016) rather than using invasive intramuscular techniques (De Luca et al. 1996). These parameters may provide information on neural strategies $(\mathrm{Hu}$ et al. 2013; Pope et al. 2016; Contessa et al. 2016) and on fiber type (Trevino et al. 2016), which could provide direct evidence to justify the assessment of the proposed differential recruitment of higher-threshold MU in children (Dotan et al. 2012). Previously, some studies have investigated these parameters in children (Herda et al. 2018; Miller et al. 2018) but none of the researchers have conducted comparisons with adults. However, reported values in children seem to differ from those obtained in adults under similar conditions (Hu et al. 2013; Stock et al. 2012). Recently, a study reported that children achieved greater firing rates in comparison to adults during repetitive muscle actions of the first dorsal interosseous (Miller et al. 2019).

These potential differences in MU recruitment patterns may also translate into differences in voluntary activation level (VA), as assessed by the twitch interpolation technique (Merton 1954). Interestingly, a lower VA was reported during maximal voluntary contractions (MVC) in prepubertal children than adults (Grosset et al. 2008; O'Brien et al. 2009; Kluka et al. 2015; Martin et al. 2015). In contrast, other studies (Hatzikotoulas et al. 2014; Ratel et al. 2015; Piponnier et al. 2018) reported a similar VA between boys and men. These divergences could be partly explained by the age of children (Grosset et al. 2008) or by the testing conditions. Indeed, the child-adult VA differences seem to be modulated by muscle length. Kluka et al. (2015) reported a similar VA between boys and men at short muscle length, whereas VA remained unchanged in boys and increased in men at a long muscle length, thereby increasing the child-adult difference in VA under specific conditions.

If the proposal of a differential recruitment of higherthreshold MU in children holds true, no difference in VA and MU recruitment patterns should be observed at low submaximal force levels between children and adults. In contrast, boys compared with men would display a lower utilization of their higher-threshold MU and a lower VA at near-maximal and maximal force levels. To date, no data are available in the literature to verify this hypothesis. Therefore, the purpose of this study was to compare VA and MU recruitment patterns between boys and men at different contraction levels of the knee extensor muscles.

\section{Materials and methods}

\section{Participants}

11 prepubertal boys (9-11 years) and 13 men (18-30 years) participated in the present study. All participants were relatively active, rather than sedentary; involved in different physical activities such as rugby, football, and swimming. To be included, boys and men had to exercise less than $4 \mathrm{~h}$ per week and be free of any medical contraindication to physical activity. The present study was approved by the local ethics committee (Protection Committee of People for Biomedical Research South-East 6; authorization number, AU 1268). All participants were fully informed of the experimental procedures and provided written consent prior to testing. In addition, the written consent of the parents/guardians was also obtained for the child participants.

\section{Study design}

Participants were tested on three occasions. The first session was dedicated to collecting participants' physical characteristics. Sessions 2 and 3 were dedicated to the assessment of VA and MU recruitment parameters of the knee extensor (KE) muscles, respectively (Fig. 1).

During the first session, physical characteristics (anthropometric measurements and maturation assessment) and clinical examinations were assessed by a medical practitioner (pediatrician for the children). Two methods were used to assess children's maturation. The first method was the Tanner stages that were determined from self-reported assessment, based on pubic hair and testicular/penis development (Tanner and Whitehouse 1976). The children were assisted by their parents while completing the questionnaire. The second was the age from peak height velocity (APHV), which was used to estimate somatic maturity and was determined using height, sitting height and body mass. Its calculation was based on sex-specific regression equations (Mirwald et al. 2002). To conclude this session, familiarization with the experimental procedures occurred that included the determination of the optimal knee angle for maximal knee extension torque. Given that the optimal angle may differ between children and adults (Marginson and Eston 2001), this angle was determined individually, in order to ascertain that each participant would produce his individually determined maximal voluntary force and ensure a fair comparison between age groups. To determine the optimal angle, participants were asked to perform two MVCs of the KE muscles at different knee angles $\left(70^{\circ}\right.$, $75^{\circ}, 80^{\circ}, 85^{\circ}, 90^{\circ} ; 0^{\circ}=$ full extension). The MVCs were performed with $2 \mathrm{~min}$ of rest between trials. The optimal 


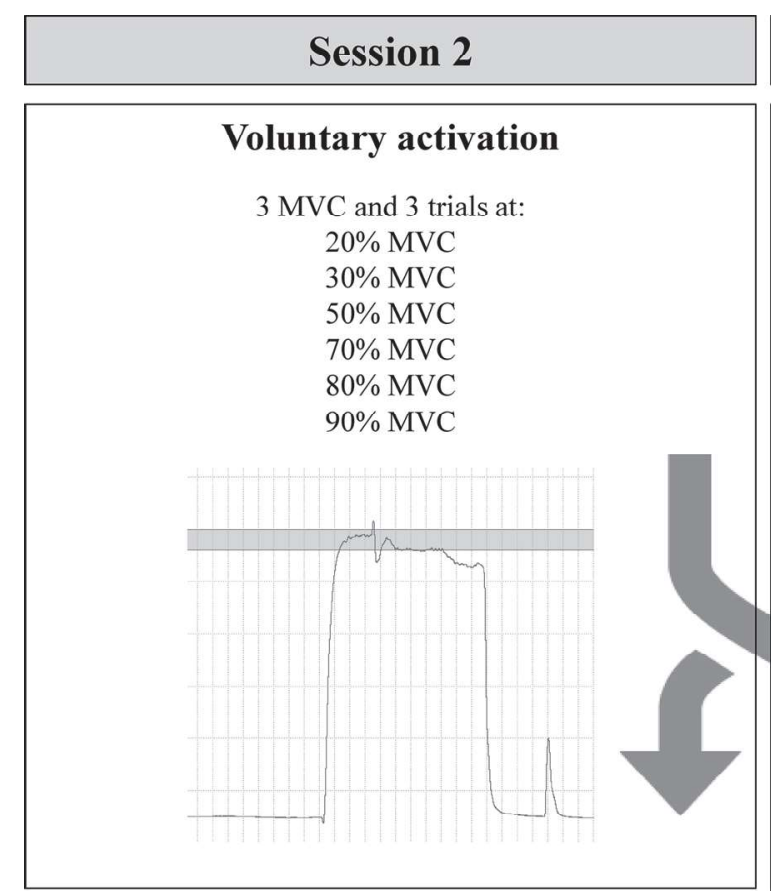

Fig. 1 Overview of the sessions 2 and 3. After the familiarization session, participants performed two sessions in a randomized order. Session 2 was dedicated to assessments of voluntary activation using the twitch interpolation technique. Session 3 was dedicated to assessment

knee angle did not differ between boys and men $\left(78.6^{\circ} \pm\right.$ $6.0^{\circ}$ vs. $75.4^{\circ} \pm 5.2$, respectively; $F(1 ; 22)=2.05, p=0.17$, $\eta^{2}=0.09$, power $=0.27$ ).

Sessions 2 and 3 were separated by 7-10 days, with tests performed in a randomized order (Fig. 1). Before the measurements, participants performed a progressive warmup (4 contractions up to $\sim 50 \% \mathrm{MVC}, 4$ contractions up to $\sim 80 \%$ MVC and 2 contractions up to a near-maximal effort; with a rest of $30 \mathrm{~s}$ between each contraction), followed by a 5-min rest time. Voluntary and evoked contractions were assessed on the right leg under isometric conditions using an isokinetic dynamometer (Biodex system 2; Biodex Medical Systems, Inc., Shirley, NY). Participants were comfortably positioned on an adjustable chair with the hip joint flexed at $60^{\circ}\left(0^{\circ}\right.$, neutral position). Straps were attached to each participant over the pelvis, trunk and contralateral thigh. The dynamometer lever arm was attached $1-2 \mathrm{~cm}$ above the lateral malleolus with a Velcro ${ }^{\circledR}$ strap. The axis of rotation of the dynamometer was aligned to the lateral femoral condyle of the right femur. During the voluntary contractions, participants were also instructed to grip the lateral handles to stabilize the pelvis. Visual feedback was provided during each contraction and strong verbal encouragement was given by the investigator. Torque data were corrected for gravity, digitized and exported at a rate of $2 \mathrm{kHz}$ to an external analog-to-digital converter (PowerLab 8/35; ADInstrument,
Session 3

EMG Decomposition

$3 \mathrm{MVC}$ and 3 trials at:

$20 \% \mathrm{MVC}$

$30 \% \mathrm{MVC}$

$50 \% \mathrm{MVC}$

$70 \%$ MVC

$80 \% \mathrm{MVC}$

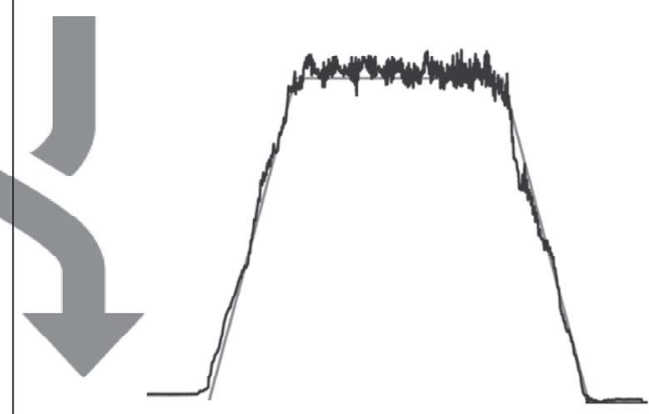

of motor unit recruitment parameters using a 5-pin electrode (Delsys, Inc., Natick, Massachusetts) during trapezoidal contractions. MVC: maximal voluntary contraction, EMG electromyography

New South Wales, Australia) driven by the LabChart 7.3 Pro software (ADInstrument, New South Wales, Australia).

\section{Session 2}

\section{Protocol}

Participants performed three 5-s MVCs at the optimal knee angle separated by 2 min of rest to determine the maximal torque of the day. To quantify VA as a function of the contraction level (see below for further details), the participants were asked to perform three 5-s contractions at $20 \%, 30 \%$, $50 \%, 70 \%, 80 \%, 90 \%$, of this MVC in a randomized order. Each contraction was followed by a rest period of $60 \mathrm{~s}$. Throughout these attempts, participants were instructed to kick out "as hard as possible" during MVCs and "as fast as possible" during submaximal contractions. The target torque level and the actual exerted torque were displayed, in real time, on the computer monitor as visual feedback.

\section{Femoral nerve stimulation}

Evoked contractions of the KE muscles were triggered by a single magnetic stimulus delivered to the femoral nerve using a figure-of-eight coil connected to two magnetic stimulators (Magstim 200², Magstim, Witland, Dyfed, UK) 
linked by the Bistim ${ }^{2}$ module (peak magnetic field strength $2.5 \mathrm{~T}$, stimulus duration $115 \mu \mathrm{s}$; Magstim, Witland, Dyfed, UK). The coil was placed high in the femoral triangle closed to the femoral nerve. Small spatial adjustments were initially performed to determine the optimal position at which the greatest unpotentiated $\mathrm{KE}$ twitch amplitude and the greatest vastus lateralis (VL) and vastus medialis (VM) M-waves amplitudes $\left(M_{\max }\right)$ were evoked. The optimal stimulation intensity, i.e., the intensity at which maximal twitch and concomitant VL and VM M-waves amplitudes started to plateau, was determined from a recruitment curve. Briefly, two single stimulations were delivered every $5 \mathrm{~s}$ at $50 \%$, $60 \%, 70 \%, 80 \%, 85 \%, 90 \%, 95 \%, 97 \%$, and $100 \%$ of the maximal stimulator power output. To overcome the potential confounding effect of axonal hyperpolarization (Burke 2002), the stimulation intensity was set to $100 \%$ of the stimulator output during the subsequent testing procedures. This intensity corresponded to $104.6 \% \pm 8.6 \%$ and $109.3 \% \pm 9.1 \%$ of the optimal intensity in the boys and men, respectively. These supra-maximal intensities were higher than the optimal intensities $[F(1,22)=15, p<0.001$, $\eta^{2}=0.41$, power $\left.=0.96\right]$ and did not differ between groups $\left[F(1 ; 22)=1.0, p=0.34, \eta^{2}=0.04\right.$, power $\left.=0.16\right]$.

\section{Voluntary activation level}

To determine VA, the twitch interpolation technique was used. Briefly, a superimposed $\left(\mathrm{Qtw}_{\mathrm{s}}\right)$ single twitch was delivered during contraction after the torque had reached a plateau for MVC or reached the target contraction level for submaximal contractions. Potentiated $\left(\mathrm{Qtw}_{\mathrm{pot}}\right)$ single twitch were delivered $3 \mathrm{~s}$ after the cessation of the contraction. These superimposed and potentiated mechanical amplitudes were used to quantify VA as proposed by Merton (1954):

$\mathrm{VA}(\%)=\left[1-\left(\mathrm{Qtw}_{\mathrm{s}} \cdot \mathrm{Qtw}_{\mathrm{pot}}^{-1}\right)\right] \cdot 100$

\section{EMG recordings}

During session 2, the EMG signals of the VL and VM were recorded using bipolar silver chloride surface electrodes (Blue Sensor N-00-S, Ambu, Denmark) during voluntary and evoked contractions. The recording electrodes were taped lengthwise on to the skin over the muscle belly (Surface ElectroMyography for the Non-Invasive Assessment; Hermens et al. 2000), with an inter-electrode distance of $20 \mathrm{~mm}$. Low impedance $(Z<5 \mathrm{k} \Omega)$ at the skin-electrode surface was obtained by shaving, gently abrading the skin with thin sandpaper and cleaning with alcohol. EMG signals were amplified (Dual Bio Amp ML 135, ADInstruments, Australia) with a bandwidth frequency ranging from 10 to $500 \mathrm{~Hz}$ (common mode rejection ratio $>85 \mathrm{~dB}$, gain $=1000$ ) and simultaneously digitized together at a rate of $2 \mathrm{kHz}$ with the torque signals using the external analog-to-digital converter. Root mean square (RMS) values of the VL and VM were calculated within the 300-ms analysing window, located before the stimulation artefact. RMS values were normalized to the corresponding M-wave peak-to-peak amplitude (RMS/ $\mathrm{M}_{\max }$ ), evoked $3 \mathrm{~s}$ after the cessation of the contraction.

\section{Session 3}

\section{Protocol}

Participants performed three 5-s MVCs at the optimal knee angle separated by 2 min of rest to determine the maximal torque of the day. Then, participants performed at least two trapezoidal contractions at $20 \%$ of this MVC to check the quality of VL and VM signals. Finally, to compare MU recruitment patterns between boys and men, the participants performed three isometric trapezoidal contractions at $20 \%, 30 \%, 50 \%, 70 \%$ and $80 \%$ of MVC in a randomized order. Each contraction was followed by a rest period of $60 \mathrm{~s}$. For each contraction, torque was increased at a rate of $10 \% \mathrm{MVC} / \mathrm{s}$ to the target torque, which was held for $10 \mathrm{~s}$ and then decreased at a rate of $10 \% \mathrm{MVC} / \mathrm{s}$ back to baseline (Miller et al. 2017). The target trajectory and exerted torque were displayed, in real time, on the computer monitor as visual feedback.

\section{EMG decomposition}

During session 3, EMG signals of the VL and VM were recorded using a 5-pin electrode (Delsys, Inc., Natick, Massachusetts) during trapezoidal contractions. The diameter of each pin was $0.5 \mathrm{~mm}$ with the pins positioned at the corners of the $595 \mathrm{~mm}$ electrode, with the fifth pin in the center of the square electrode. The sensors were placed on VL and VM on the same locations as session 2. To check that the subcutaneous fat layer thickness of the thigh was not different between groups, it was measured using a B-mode ultrasound with a linear array transducer. Adipose tissue thicknesses over the VL muscle were $6.5 \pm 1.5$ and $7.3 \pm 2.9 \mathrm{~mm}$ in boys and men, respectively $[F(1 ; 22)=0.71, p=0.41$, $\eta^{2}=0.03$, power $\left.=0.13\right]$. The signals from four pairs of electrode pins were differentially amplified (Gain: 1000; bandwidth: 20-450 Hz; common mode rejection ratio: $100 \mathrm{~dB}$; Bagnoli ${ }^{T M}$ EMG Sytem, Delsys, Inc., Natick, Massachussetts) and synchronized with the torque data using an analog breakout accessory (BNC-2090A, National Instruments, Austin, TX USA). Signals were digitalized using an external analog-to-digital converter (NI USB-6251, National Instruments, Austin, TX USA) at a rate of $20 \mathrm{kHz}$ and driven by EMGwork software (Delsys, Inc., Natick, Massachussetts). 
The EMG signals were bandpass filtered (zero phase fourthorder Butterworth filter) at $10-500 \mathrm{~Hz}$, while the force signal was low-pass filtered with a $10-\mathrm{Hz}$ cutoff (zero phase fourth-order Butterworth filter). Data were exported on the dEMGanalysis software (Delsys, Inc., Natick, Massachussetts, USA).

The firing events of MU were extracted from the EMG signals using the precision decomposition (PD) III algorithm (De Luca et al. 2006). The PD III was specifically designed for extracting surface EMG signals into MU action potential trains (Nawab et al. 2010). Only MUs that were extracted with $>90 \%$ accuracies were included in the final analysis. For each MU, mean firing rate (MFR), recruitment threshold (RT) and MU action potential sizes (MUAP SIZE $\left._{\text {( }}\right)$ were computed (Fig. 2). The MFR was calculated from an 8-s interval in which the firing rate was stable, and the force was relatively constant at the steady state (Fig. 3a). A 2-s Hanning window was applied to the MFR curves (Fig. 3a).
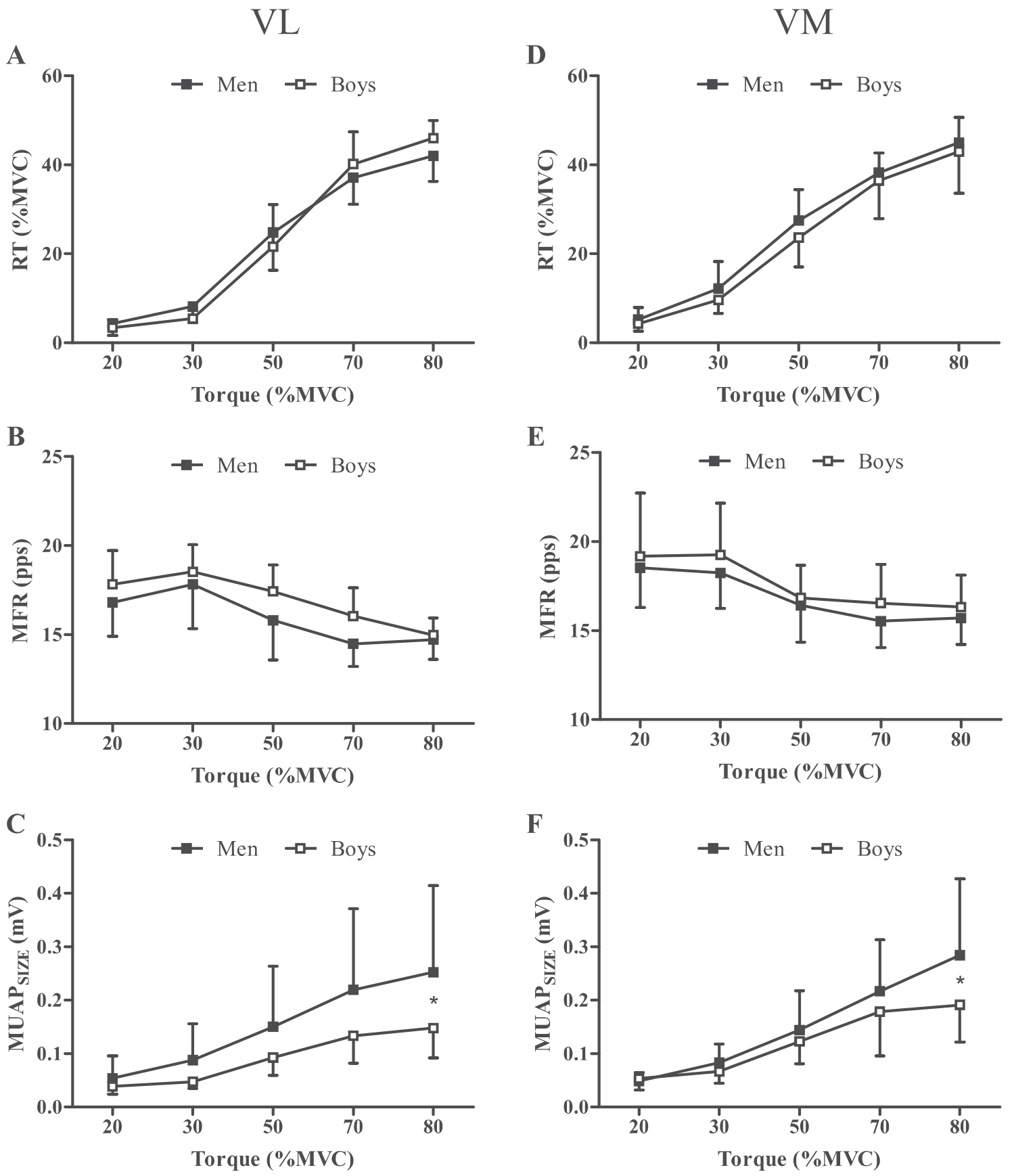

Fig. 2 Mean (SD) values of the motor unit recruitment parameters in vastus lateralis (VL; a-c) and vastus medialis (VM; d-f) muscles. RT: recruitment threshold, $M F R$ mean firing rate, $M U A P_{S I Z E}$ motor unit action potential size, $M V C$ maximal voluntary contraction. ${ }^{*} p<0.05$ 


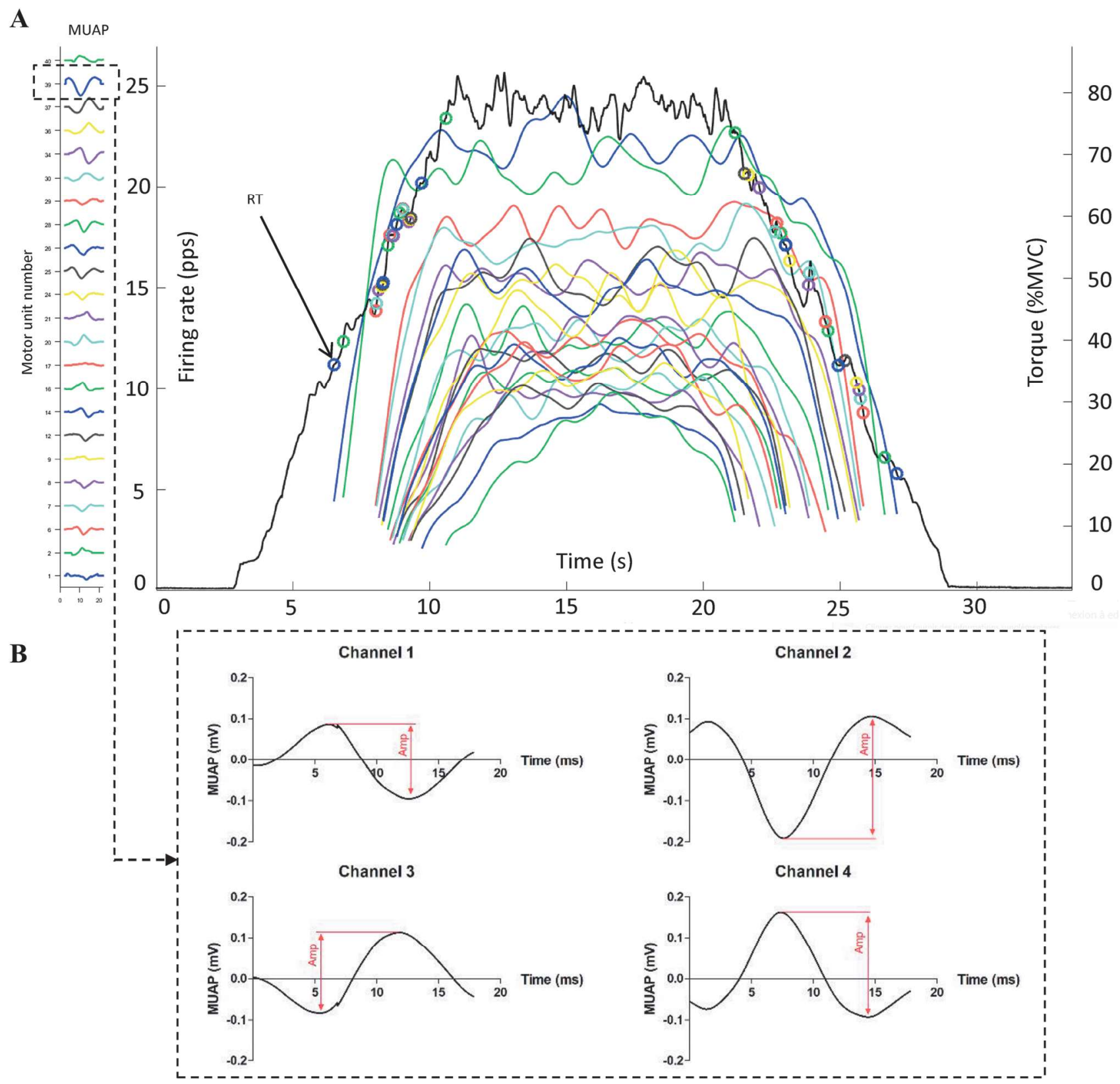

Fig. 3 Example of a trapezoidal contraction at $80 \%$ of the maximal voluntary contraction (MVC) for a boy (a) and four unique motor unit action potential (MUAP) waveforms (b). Note that these 4 poten- tials all represent the same MU recorded from each of the four different channels. $R T$ recruitment threshold, $p p s$ pulse per second, Amp amplitude

For each participant and contraction level, linear regressions were performed for the MFR vs. RT relationships (Fig. 4a) with the y-intercepts and slopes used for subsequent statistical analysis. The y-intercept was considered as the theoretical MFR for an MU recruited at 0\% MVC, and the slope as the coefficient of MFR decreases with increments in RT. Bravais-Pearson's correlation were used to test relationship significance individually.

In addition, exponential models were applied to the MUAP $_{\text {SIZE }}$ vs. RT (Eq. 2; Fig. 4b) and MFR vs. MUAP et al. 2017). 


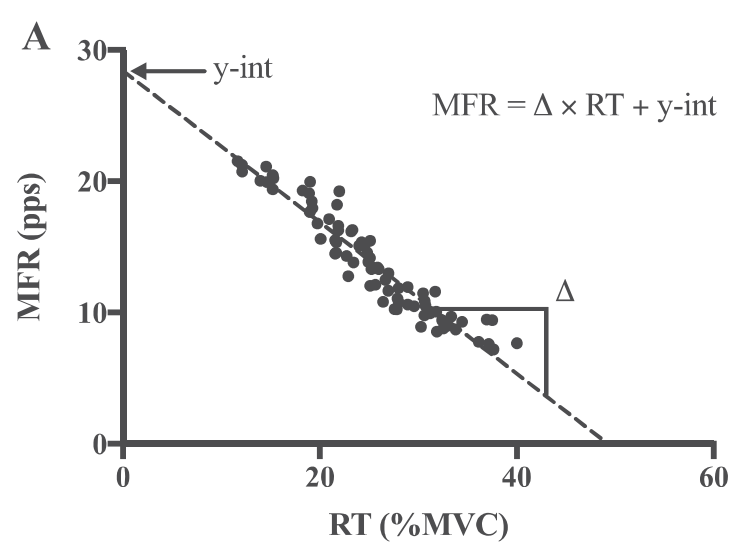

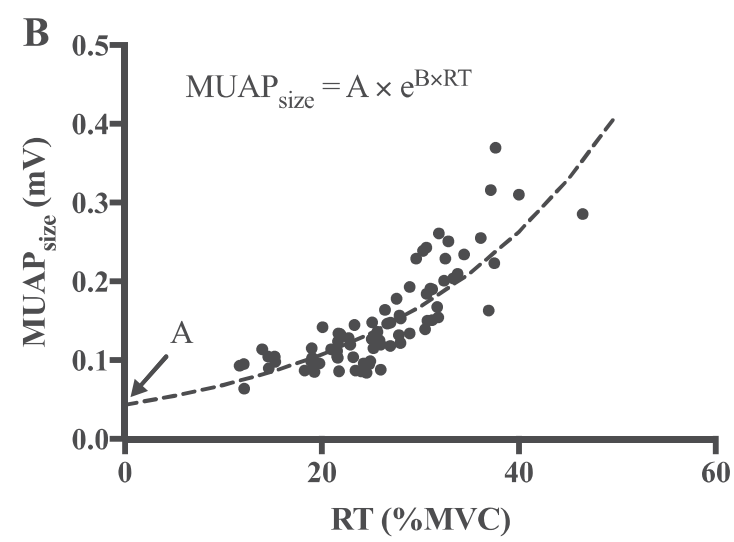

Fig. 4 Relationships for a typical participant for a trapezoidal contraction at $50 \%$. a MFR vs. RT; b MUAP SIZE $_{\text {v. }}$ RT; c MFR vs. MUAP $_{\text {SIZE }} \cdot M F R$ mean firing rate, $p p s$ pulse per second, $R T$ recruit-

(Eq. 3; Fig. 4c) relationships (Contessa et al. 2016). Spearman correlations were used to test relationship significance individually:

$\operatorname{MUAP}_{\mathrm{SIZE}}=A \cdot \mathrm{e}^{B \cdot \mathrm{RT}}$,

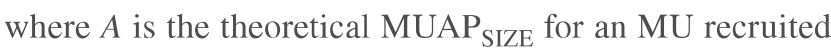
at $0 \% \mathrm{MVC}$ and $B$ represents the growth coefficient of MUAP $_{\text {SIZE }}$ with increments in RT. $A$ higher $B$ indicates that the MUs size is larger for a given RT:

$\mathrm{MFR}=A \cdot \mathrm{e}^{B \cdot \mathrm{MUAP}_{\mathrm{SIZE}}}$,

where $A$ is the theoretical MFR of an MUAP SIZE $_{\text {of } 0 \mathrm{mV}}$ and $B$ is the decay coefficient of MFR with increments in MUAP $_{\text {SIZE }}$ A smaller $B$ indicates a higher MFR for a given size of MUs (Hu et al. 2013).

Any relationship in which the RT range was $<6 \% \mathrm{MVC}$ for the $20 \% \mathrm{MVC}$ and $30 \% \mathrm{MVC},<15 \% \mathrm{MVC}$ for the $50 \%$ $\mathrm{MVC}$, and <25\% MVC for the 70\% MVC and 80\% MVC was excluded from further analysis. For each contraction level, the trial with the largest RT range was selected for final analysis. Mean (SD) values are provided in Table 1.

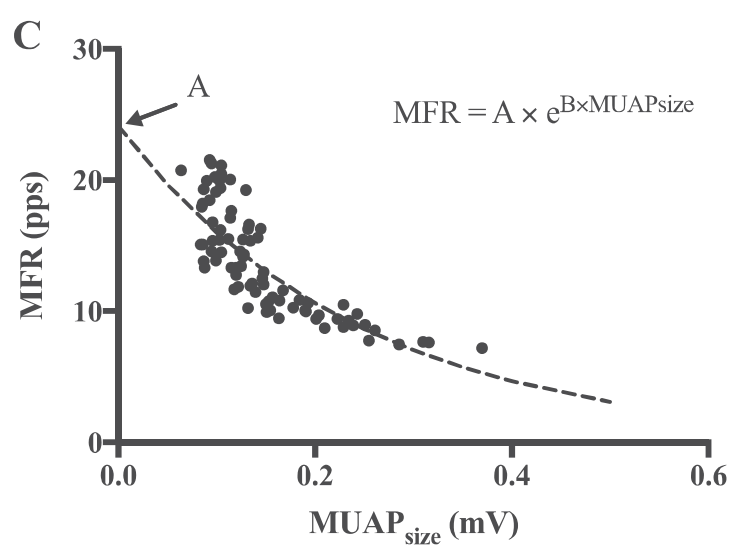

ment threshold, $M V C$ maximal voluntary contraction, MUAP SIZE motor unit action potential size, $y$-int $y$-intercept, unfilled triangle slope

\section{Statistical analysis}

Data were screened for normal distribution and homogeneity of variances using Shapiro-Wilk normality test and the Bartlett test, respectively. Student's t tests for unpaired samples were used to compare the optimal angle between groups. Torque, VA, and EMG parameters were analyzed using two-way ANOVAs (age group $\times$ contraction level) with repeated measures. When the ANOVA revealed a significant interaction, a Newman-Keuls post hoc test was applied to test the differences between means. The effect sizes and statistical power were also computed when significant main or interaction effects were detected. The effect size was assessed using the partial eta-squared $\left(\eta^{2}\right)$ and ranked as follows: $\sim 0.01=$ small effect, $\sim 0.06=$ moderate effect, $\geq 0.14=$ large effect (Cohen 1969). Statistical tests were performed using the Statistica 8.0 sofware (StatSoft, Inc, USA). Data are reported as mean \pm standard deviation (SD). The $\alpha$-level for statistical significance was set at $p<0.05$. 
Table 1 Mean (SD) values for each variable extracted from trapezoidal contractions at all contraction levels

\begin{tabular}{|c|c|c|c|c|c|}
\hline & $20 \% \mathrm{MVC}$ & $30 \% \mathrm{MVC}$ & $50 \% \mathrm{MVC}$ & $70 \% \mathrm{MVC}$ & $80 \% \mathrm{MVC}$ \\
\hline & $V L$ & & & & \\
\hline \multicolumn{6}{|l|}{ MUs } \\
\hline Men & $20.2(2.9)$ & $22.2(5.08)$ & $22.8(3.03)$ & $20.5(4.5)$ & $20.8(3.5)$ \\
\hline Boys & $20.3(3.9)$ & $23.3(3.8)$ & $22.4(5.3)$ & $21.6(4.6)$ & $20.6(4.6)$ \\
\hline \multicolumn{6}{|c|}{ RT range } \\
\hline Men & $1.6-10.5$ & $2.5-18.4$ & $13.9-40.1$ & $24.2-55.4$ & $27.0-62.3$ \\
\hline \multirow[t]{2}{*}{ Boys } & $1.1-8.8$ & $1.4-11.6$ & $10.0-37.5$ & $21.8-56.2$ & $27.8-61.7$ \\
\hline & rvalues & & & & \\
\hline \multicolumn{6}{|c|}{ MFR vs. RT } \\
\hline Men & $0.85(0.09)$ & $0.85(0.08)$ & $0.89(0.05)$ & $0.90(0.05)$ & $0.90(0.07)$ \\
\hline Boys & $0.73(0.14)$ & $0.79(0.13)$ & $0.85(0.07)$ & $0.85(0.07)$ & $0.86(0.08)$ \\
\hline \multicolumn{6}{|c|}{ MUAP $_{\text {SIZE }}$ vs. RT } \\
\hline Men & $0.77(0.10)$ & $0.75(0.09)$ & $0.83(0.08)$ & $0.82(0.09)$ & $0.81(0.08)$ \\
\hline Boys & $0.70(0.12)$ & $0.68(0.12)$ & $0.74(0.13)$ & $0.74(0.10)$ & $0.68(0.13)$ \\
\hline \multicolumn{6}{|c|}{ MFR vs. MUAP SIZE $_{1}$} \\
\hline Men & $0.88(0.07)$ & $0.86(0.06)$ & $0.87(0.04)$ & $0.85(0.07)$ & $0.83(0.07)$ \\
\hline \multirow[t]{2}{*}{ Boys } & $0.78(0.08)$ & $0.77(0.07)$ & $0.82(0.05)$ & $0.83(0.06)$ & $0.77(0.08)$ \\
\hline & $V M$ & & & & \\
\hline \multicolumn{6}{|l|}{ MUs } \\
\hline Men & $21.5(3.8)$ & $21(3.8)$ & $20.9(5.2)$ & $19.6(4.1)$ & $18.6(4.8)$ \\
\hline Boys & $17.1(2.9)$ & $21.6(4.2)$ & $19.3(6.2)$ & $20.4(4.6)$ & $20.0(4.1)$ \\
\hline \multicolumn{6}{|c|}{ RT range } \\
\hline Men & $1.8-10.5$ & $5.6-22.5$ & $16.7-41.3$ & $14.6-58.0$ & $29.0-64.0$ \\
\hline \multirow[t]{2}{*}{ Boys } & $1.7-10.1$ & $1.9-21.1$ & $12.2-35.4$ & $20.5-55.2$ & $24.6-61.6$ \\
\hline & $r$ values & & & & \\
\hline \multicolumn{6}{|c|}{ MFR vs. RT } \\
\hline Men & $0.82(0.12)$ & $0.89(0.05)$ & $0.89(0.06)$ & $0.83(0.09)$ & $0.88(0.06)$ \\
\hline Boys & $0.71(0.15)$ & $0.80(0.12)$ & $0.86(0.06)$ & $0.83(0.06)$ & $0.78(0.10)$ \\
\hline \multicolumn{6}{|c|}{ MUAP $_{\text {SIZE }}$ vs. RT } \\
\hline Men & $0.77(0.10)$ & $0.79(0.11)$ & $0.82(0.08)$ & $0.80(0.10)$ & $0.79(0.12)$ \\
\hline Boys & $0.69(0.14)$ & $0.76(0.11)$ & $0.80(0.09)$ & $0.78(0.09)$ & $0.70(0.09)$ \\
\hline \multicolumn{6}{|c|}{ MFR vs. MUAP $_{\text {SIZE }}$} \\
\hline Men & $0.88(0.08)$ & $0.87(0.07)$ & $0.88(0.06)$ & $0.85(0.09)$ & $0.82(0.08)$ \\
\hline Boys & $0.78(0.09)$ & $0.83(0.04)$ & $0.82(0.07)$ & $0.82(0.08)$ & $0.79(0.06)$ \\
\hline
\end{tabular}

Data are the number of motor units (MUs) recorded, recruitment threshold (RT) range [expressed as a \%maximal voluntary contraction torque (MVC)], and $\mathrm{r}$ values of the vastus lateralis (VL) and vastus medialis (VM)

\section{Results}

\section{Participants' characteristics}

The mean age, stature, body mass and body mass index in boys were $10.3 \pm 0.7$ years, $1.38 \pm 0.07 \mathrm{~m}, 31.8 \pm 4.4 \mathrm{~kg}$ and $16.7 \pm 1.4 \mathrm{~kg} . \mathrm{m}^{-2}$, respectively. These respective values for men were $23.8 \pm 3.1$ years, $1.78 \pm 0.07 \mathrm{~m}, 72.4 \pm 8.5 \mathrm{~kg}$ and $22.8 \pm 1.8 \mathrm{~kg} \cdot \mathrm{m}^{-2}$. All the boys were prepubertal (Tanner stages I and II). Their age at the peak height velocity was $13.5 \pm 0.5$ years, and their chronological age was approximately $-3.4 \pm 0.5$ years from APHV.

\section{Torque and VA}

Torque ANOVA revealed a significant interaction effect (age group $\times$ contraction level) for absolute MVC torque value $\left[F(6 ; 132)=113.27, p<0.001, \eta^{2}=0.84\right.$, power $\left.=1.0\right]$. As expected, the maximal voluntary isometric torque of the $\mathrm{KE}$ was significantly lower in children than their adult counterparts $(93.7 \pm 21.2$ vs. $301.5 \pm 60.9 \mathrm{~N}$ m, respectively; $p<0.001)$.

Voluntary activation ANOVA revealed no significant interaction or age group effect for VA. Only a contraction level effect was found $[F(6 ; 132)=607.38, p<0.001$, 
$\eta^{2}=0.97$, power $\left.=1.0\right]$ (Fig. 5). The VA increased with the contraction level regardless of the age group.

Normalized EMG ANOVA revealed no significant interaction or age group effect but showed a significant main

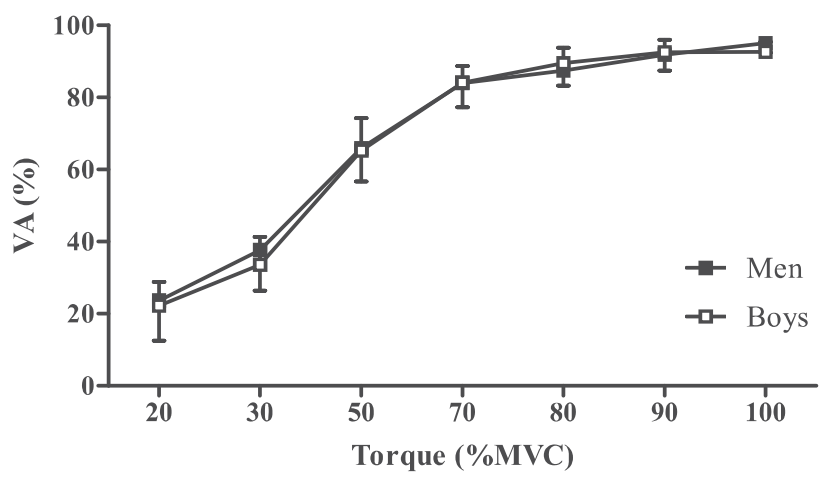

Fig. 5 Relationship between voluntary activation level (VA) and relative torque to maximal voluntary contraction (MVC). No significant difference was observed between groups
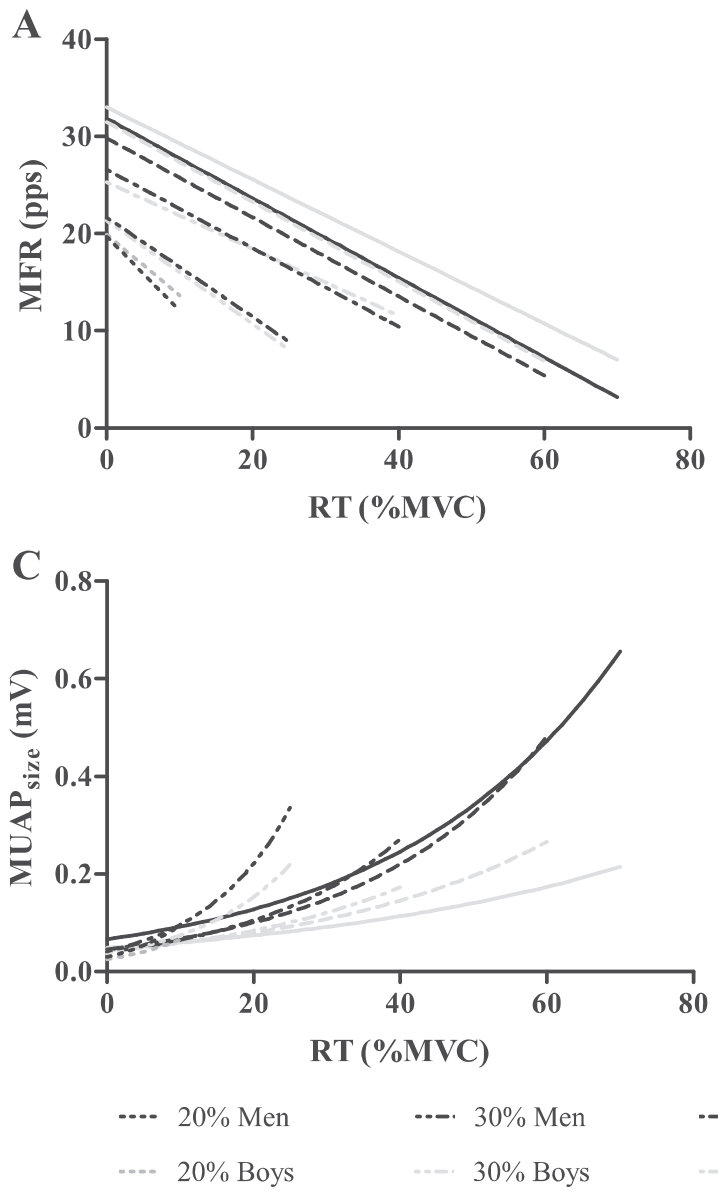

Fig. 6 Mean predictions of the MFR vs. RT relationships for boys and men on vastus lateralis (a) and vastus medialis (b) muscles. Mean predictions of the MUAP size $_{\text {vs. RT relationships for boys and }}$ effect for contraction level for the RMS/M $\mathrm{Max}_{\max }$ ratio of the VL $\left[F(6 ; 132)=108.9, p<0.001, \eta^{2}=0.83\right.$, power $\left.=1.0\right]$ and VM muscles $\left[F(6 ; 132)=86.04, p<0.001, \eta^{2}=0.80\right.$, power $=1.0]$. RMS $/ M_{\max }$ increased similarly in boys and men as a function of the contraction level.

\section{MU recruitment parameters}

$M F R$ vs. RT relationships Analyses of the regression slopes of the MFR vs. RT relationships showed no significant interaction or age group effect. Results from ANOVAs revealed only a contraction level effect for both VL $[F(4$; $88)=12.12, p<0.001, \eta^{2}=0.39$, power $\left.=1.0\right]$ and VM muscles $\left[F(4 ; 88)=5.17, p<0.001, \eta^{2}=0.21\right.$, power $\left.=0.96\right]$. Regression slopes of the MFR vs. RT relationships increased from 20 to 50\% of MVC in both age groups (Fig. 6a, b). Similarly, ANOVAs revealed no significant interaction and age group effect for the y-intercept for both VL and VM muscles. A contraction level effect was found for both muscles [VL: $F(4 ; 88)=46.06, p<0.001, \eta^{2}=0.71$, power $=1.0$
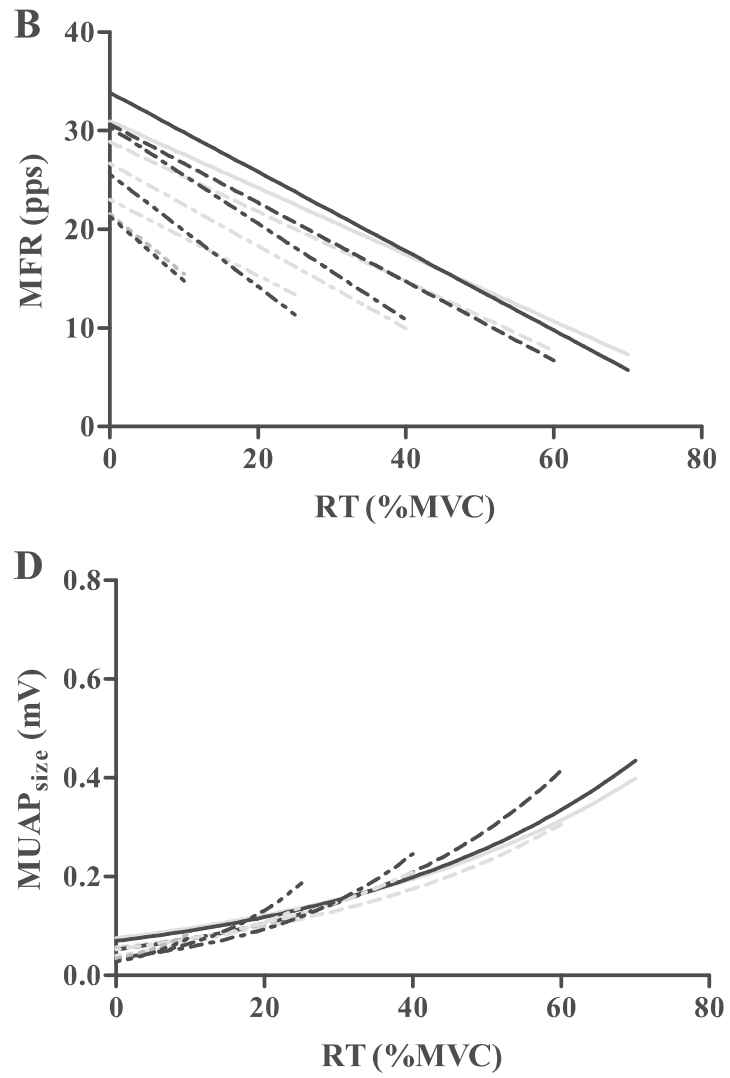

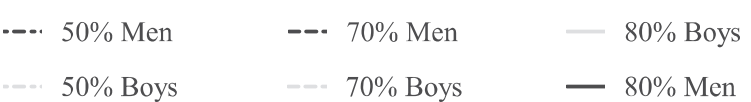

men on vastus lateralis (c) and vastus medialis (d) muscles. MUAP ${ }_{\text {size }}$ motor unit action potential size, $p p s$ pulse per second, $R T$ recruitment threshold, $M V C$ maximal voluntary contraction 
and VM: $F(4 ; 88)=22.9, p<0.001, \eta^{2}=0.55$, power $\left.=1.0\right]$. The y-intercept increased from 20 to $70 \%$ of MVC similarly in boys and men.

$M U A P_{S I Z E}$ vs. RT relationships For VL B terms, the ANOVA only revealed a significant age group effect $\left[F(1 ; 22)=4.72, p<0.05, \eta^{2}=0.20\right.$, power $\left.=0.54\right]$ and contraction level effect $\left[F(4 ; 88)=44.08, p<0.001, \eta^{2}=0.70\right.$, power $=1.0]$. Boys displayed a lower VL B term value than men across contraction levels (Fig. 7a). For VM B term, the ANOVA also revealed significant contraction level effect $\left[F(4 ; 88)=24.71, p<0.001, \eta^{2}=0.57\right.$, power $\left.=1.0\right]$ and an age group effect tended to appear $[F(1 ; 22)=2.99, p=0.10$, $\eta^{2}=0.14$, power $\left.=0.38\right]$. Boys displayed a lower VL B term value than men across contraction levels ( $p<0.05$; Fig. $7 \mathrm{a})$. In addition, B terms decreased from 20 to $50 \%$ of MVC for each age group and both muscles (Fig. 6c, d). For the A term, there was neither a significant interaction nor an age group effect for both muscles. Only a contraction level effect was found [VL: $F(4 ; 88)=10.81, p<0.001, \eta^{2}=0.35$, power $=1.0$ and VM: $F(4 ; 88)=14.85, p<0.001, \eta^{2}=0.44$, power $=1.0]$. The A term increased from 50 to $80 \%$ of MVC similarly in boys and men for VL and VM muscles.

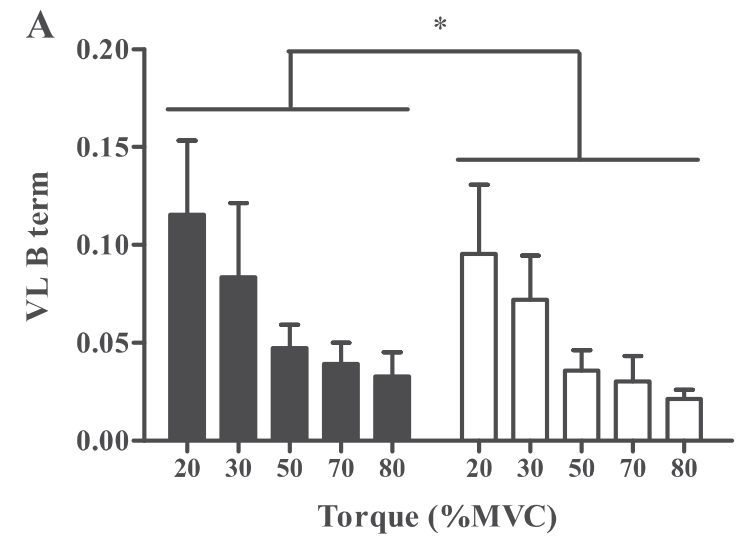

C

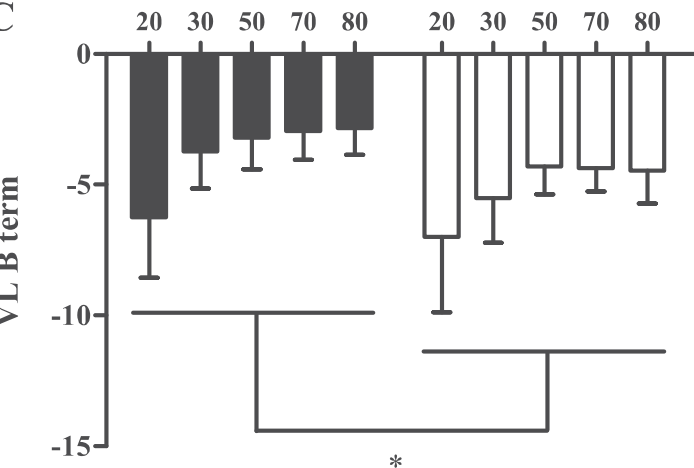

Men

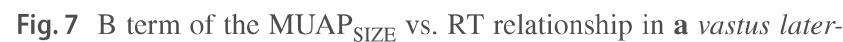
alis (VL) muscle and b vastus medialis (VM) muscle. b Term of the MFR vs. MUAP ${ }_{\text {SIZE }}$ relationship in $\mathbf{c}$ VL muscle and d VM muscle.
$M F R$ vs. $M U A P_{\text {SIZE }}$ relationships For VL B term, the ANOVA did not reveal any significant interactions. However, there were significant age group $[F(1 ; 22)=6.47$, $p<0.05, \eta^{2}=0.25$, power $\left.=0.67\right]$ and contraction level effects $\left[F(4 ; 88)=23.37, p<0.001, \eta^{2}=0.55\right.$, power $\left.=1.0\right]$. Boys displayed a lower VL B term than men independent of the contraction level ( $p<0.05$; Fig. $7 c)$. For VM B terms, no significant interaction was found. However, a significant main effect of the contraction level was found $\left[F(4 ; 88)=15.83, p<0.001, \eta^{2}=0.43\right.$, power $\left.=1.0\right]$ and an age group effect tended to appear $[F(1 ; 22)=2.23$, $p=0.15, \eta^{2}=0.09$, power $\left.=0.30\right]$. VM B term tended to be lower in boys than men regardless of the contraction level (Fig. 7d). In addition, B terms of the MFR vs. MUAP $_{\text {SIZE }}$ relationships increased from 20 to $50 \%$ and 20 to $70 \%$ of MVC in VL and VM muscles, respectively, independent of the age group. Similarly, for the A terms, there was neither a significant interaction nor an age group effect, but there was a contraction level effect for both VL $\left[F(4 ; 88)=8.57, p<0.001, \eta^{2}=0.31\right.$, power $\left.=1.0\right]$ and $\mathrm{VM}$ muscles $\left[F(4 ; 88)=2.52, p<0.05, \eta^{2}=0.11\right.$, power $\left.=0.69\right]$. The A term increased from 20 to $50 \%$ and 20 to $30 \%$ of the
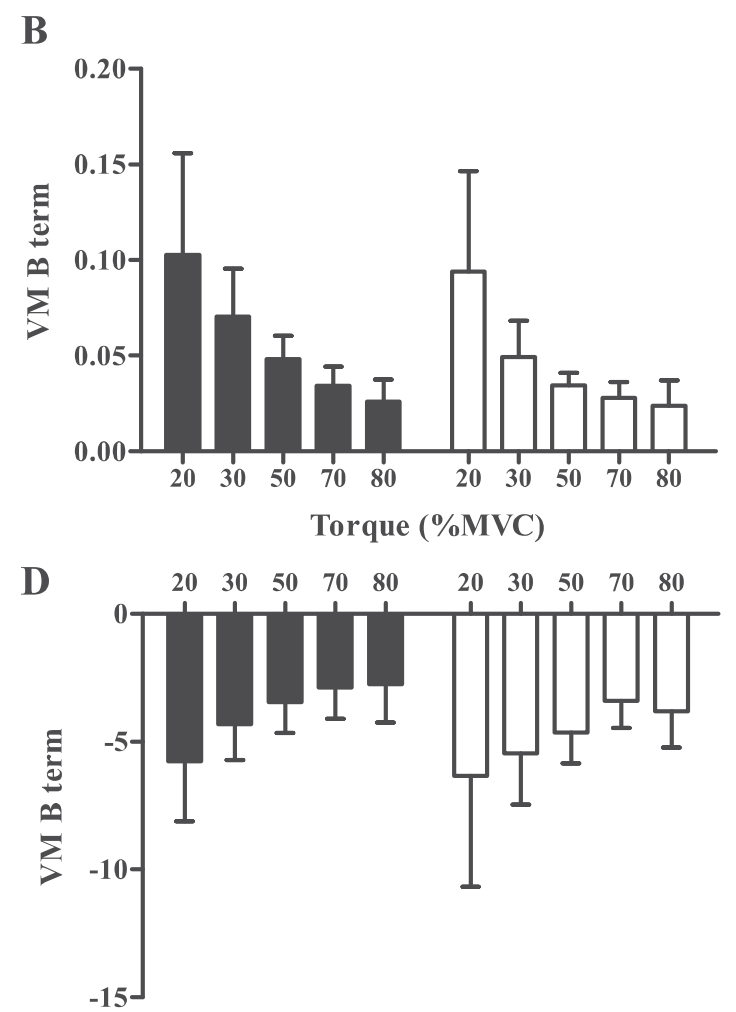

$\square$ Boys

$M U A P_{\text {SIZE }}$ motor unit action potential size, $R T$ recruitment threshold, pps pulse per second, $M F R$ mean firing rate, $M V C$ maximal voluntary contraction. $* p<0.05$ 
MVC in VL and VM muscles, respectively, independent of the age group.

\section{Discussion}

The purpose of this study was to compare VA and MU recruitment patterns between boys and men at different contraction levels of the knee extensor muscles. We hypothesized that boys and men would display similar VA and MU recruitment patterns at low submaximal force levels, but that boys compared with men would display a lower utilization of their higher-threshold MU and a lower VA at near-maximal and maximal force levels. However, the results of the present study only partly supported our assumptions. No difference between boys and men was found for VA regardless of the contraction level investigated. Slight age group differences were observed among MU recruitment patterns.

In the present study, no boys-men differences in VA and normalized EMG were observed at all contraction levels investigated. The similar VA between boys and men at low submaximal contraction level was expected and supported our assumption. Near-maximal and maximal results supported neither our hypothesis nor the proposal raised by Dotan et al. (2012; Dotan 2016). The authors suggested a decreased utilization of the higher-threshold MU in children that should translate into a lower VA in children than adults during near-maximal and maximal contractions. However, our results showed no difference in VA between children and adults during maximal effort. This result is also inconsistent with previous studies showing lower VA in children than adults during MVC (Kluka et al. 2015; Martin et al. 2015). These divergences could be partly explained by the age of children and large interindividual variations. Indeed, VA differences seem evident when children aged 6-8 years are used in comparison with adults (Belanger and McComas 1989; Grosset et al. 2008) but when the recruited children are 10 years or older, differences between children and adults remain controversial. Some studies have reported a lower VA in children than adults (O'Brien et al. 2009; Kluka et al. 2015; Martin et al. 2015), while others have found no VA difference between age groups (Streckis et al. 2007; O’Brien et al. 2010; Hatzikotoulas et al. 2014; Ratel et al. 2015; Piponnier et al. 2018). It seems that the age of 10 years corresponds to the period at which some children can reach VA values comparable to adults, whereas others do not. This controversy was also displayed in findings of Koh and Eyre (1988) who showed that the excitability of the corticospinal tract increased dramatically between 8 and 11 years. In addition, it is possible that inconsistent findings among studies may be ascribed to testing conditions. It has indeed been shown that muscle length modulates VA differences between children and adults (Kluka et al. 2015) when comparing short and long muscle lengths. In the current study, the optimal muscle length was chosen to maximize torque production and ensure a fair comparison between groups, given that the optimal angle may vary between children and adults (Marginson and Eston 2001). Interestingly, some studies comparing children and adults at the optimal muscle length did not report any maximal VA difference on the KE muscles between children and adults (Ratel et al. 2015; Piponnier et al. 2018), which is consistent with the current findings.

The VA results are fully consistent with the extracted EMG parameters, since no difference in MU recruitment patterns was observed between boys and men at all contraction levels investigated. In the present study, EMG extraction provided evidence that boys and men displayed similar neural strategies to perform isometric submaximal voluntary contractions. The MFR vs. RT relationships indicated that the MFR increased with the contraction level (Fig. 6a), which is consistent with the temporal recruitment principle (Kukulka and Clamann 1981). This relationship may provide indirect evidence that the neural strategies and the muscle fiber type composition were similar in boys and men. Indeed, it is acknowledged that MFR is representative of the properties of the motor neurons (De Luca and Erim 1994; Hu et al. 2013), but we found no significant difference between boys and men. This absence of age-related difference is inconsistent with several studies (Dotan et al. 2012; Pitt et al. 2015; Long et al. 2017), who postulated that children would be less able to recruit or utilize their higher-threshold MU (Type II). Such inconsistencies could be explained by the different methods used to characterize MU recruitment patterns. Indeed, the methods used in the above-mentioned studies (Dotan et al. 2012; Pitt et al. 2015; Long et al. 2017) were indirect methods. For instance, Dotan et al. (2012) interpreted that a longer electromechanical delay in boys than men may suggest a lower utilization of higher-threshold MU, yet this parameter could also be affected by the musculotendinous stiffness (Cavanagh and Komi 1979). Similarly, a lower utilization of faster MU in children was suggested by their higher electromyographic threshold (Pitt et al. 2015; Long et al. 2017), but this parameter could be also affected by the different metabolic profile between boys and men (Ertl et al. 2016).

In the current study, the negative slope of the MFR vs. RT relationship, which correlates with a higher percentage of type I MHC isoform content (Trevino et al. 2016), did not differ between children and adults. This is inconsistent with the study of Lexell et al. (1992), who found a higher percentage of type I fibers in children. However, their conclusion was based on a relationship between age (5-37 years) and proportion of type I fibers, including a limited number of prepubertal children $(n=3)$. Moreover, we found a similar $y$-intercept of the MFR vs. RT relationship between men 
and boys. This is inconsistent with the results of Miller et al. (2019), who found that children achieved greater firing rates in comparison to adults during muscle actions of the first dorsal interosseous. It is likely that the divergent findings are a result of the muscles tested.

Moreover, the $\mathrm{MUAP}_{\text {SIZE }}$ vs. RT relationships indicated that the later higher-threshold MUs were larger in amplitude and associated with an increase of contraction level, which conforms to the Henneman size principle (Henneman et al. 1965). In the present study, the growth coefficient was higher in men than boys for VL muscle and tended to be higher for VM muscle. It might be interpreted as an earlier recruitment of large and fast MU. This result could be considered consistent with previous studies suggesting an earlier and reduced utilization of type II fibers in children (Dotan et al. 2012; Pitt et al. 2015; Long et al. 2017). However, such differences between groups could also be explained by larger muscle fiber sizes in adults than children. Indeed, it is acknowledged that MUAP $_{\text {SIZE }}$ is sensitive to changes in muscle fiber sizes (Pope et al. 2016).

Similarly, the MFR vs. MUAP ${ }_{\text {SIZE }}$ relationships might also be affected by the fiber sizes (Pope et al. 2016) and, therefore, muscle dimensions (Trevino et al. 2018). In the present study, the MFR for a given MUAP $_{\text {SIZE }}$ was higher in adults than children for the VL muscle and tended to be higher for the VM muscle. However, for a given $\mathrm{MUAP}_{\mathrm{SIZE}}$, the RT should be lower in adults than children, and the associated MFR should be higher, according to the onion-skin phenomenon (De Luca et al. 1982). Therefore, it is likely that the difference in muscle fiber size between groups

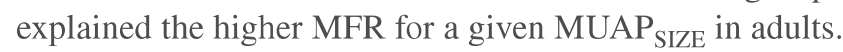
This suggests that data derived from EMG decomposition techniques should be normalized to muscle/fiber dimensions when comparing groups with different muscle dimensions. Nevertheless, the appropriate normalization procedure remains uncertain.

A few limitations of our study could be noted. Firstly, VA and MU data were not assessed during the same session for technical reasons. However, torque levels did not differ between sessions. Contraction shapes were different between sessions, because of different methodological requirements for MU recruitment pattern and VA assessment. Contraction type has been shown to influence muscle activation and force output (Tomko et al. 2018). However, boys and men performed the same protocol. The relative torques were not different between the groups; therefore, there is no apparent physiological reason that the contraction shapes differentially affect neural strategies in the examined groups. The second potential limitation was the interpolated twitch technique method used in the present study. A single stimuli could increase the measurement variability (Suter and Herzog 2001) and/or decrease the signal-to-noise ratio (Kent-Braun and Le Blanc 1996). However, the enhanced reliability of multiple pulses already observed (Kent-Braun and Le Blanc 1996; Herbert et al. 1997; Suter and Herzog 2001) remains controversial, as several authors have observed similar results using single or multiple stimuli (Behm et al. 1996; Allen et al. 1998). In the current project, for ethical reason, it was not possible to use doublet stimuli because the protocol was potentially painful for children. Ethical constraints may explain why several studies also used single stimulation to assess VA in this population (Kluka et al. 2015; Ratel et al. 2015; Piponnier et al. 2018). The third limitation of the current study is the meth-

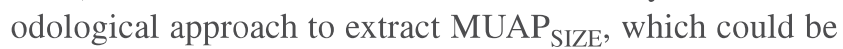
affected by subcutaneous fatty tissue, electrode placement, or impedance (De Luca 1997). However, the subcutaneous fat thickness did not differ between populations. The electrode placement may nevertheless affect our results. Indeed, this EMG decomposition technique only allows MU identification within a restricted portion of the muscle. The use of high-density surface EMG arrays could help in confirming the obtained results due to their larger detection area (Merletti et al. 2008).

To conclude, no difference between boys and men was found for VA independent of the contraction level investigated. Some differences in motor unit recruitment parameters between boys and men were observed but seem to be explained by different muscle dimensions between groups. This underlies the need to design well-considered normalization procedures for the EMG decomposition technique when testing populations with different muscle dimensions.

Acknowledgements The authors are grateful to Pr. Geraldine Naughton for the edition of the manuscript, and Pr. Daniel Courteix for his help with the statistical analysis.

Author contributions The study was designed by EC, EP, BB, SR and VM. EC, EP, BB, VJ, OB, MD, SR and VM contributed to the data collection, data analysis and interpretation of the data, drafting, and revising the manuscript. All authors approved the final version of the manuscript.

\section{Compliance with ethical standards}

Conflict of interest No conflicts of interest, financial or otherwise, are declared by the authors.

\section{References}

Allen GM, McKenzie DK, Gandevia SC (1998) Twitch interpolation of the elbow flexor muscles at high forces. Muscle Nerve 21:318-328

Behm DG, St-Pierre DM, Perez D (1996) Muscle inactivation: assessment of interpolated twitch technique. J Appl Physiol (1985) 81:2267-2273. https://doi.org/10.1152/jappl.1996.81.5.2267

Belanger AY, McComas AJ (1989) Contractile properties of human skeletal muscle in childhood and adolescence. Eur J Appl Physiol 58:563-567 
Burke D (2002) Effects of activity on axonal excitability: implications for motor control studies. Adv Exp Med Biol 508:33-37

Cavanagh PR, Komi PV (1979) Electromechanical delay in human skeletal muscle under concentric and eccentric contractions. Eur J Appl Physiol 42:159-163

Cohen J (1969) Statistical power analysis for the behavioral sciences. Academic Press, New York

Contessa P, De Luca CJ, Kline JC (2016) The compensatory interaction between motor unit firing behavior and muscle force during fatigue. J Neurophysiol 116:1579-1585. https://doi.org/10.1152/ jn.00347.2016

De Luca CJ (1997) The use of surface electromyography in biomechanics. J Appl Biomech 13:135-163. https://doi.org/10.1123/ jab.13.2.135

De Luca CJ, Erim Z (1994) Common drive of motor units in regulation of muscle force. Trends Neurosci 17:299-305

De Luca CJ, LeFever RS, McCue MP, Xenakis AP (1982) Behaviour of human motor units in different muscles during linearly varying contractions. J Physiol 329:113-128

De Luca CJ, Foley PJ, Erim Z (1996) Motor unit control properties in constant-force isometric contractions. J Neurophysiol 76:15031516. https://doi.org/10.1152/jn.1996.76.3.1503

De Luca CJ, Adam A, Wotiz R et al (2006) Decomposition of surface EMG signals. J Neurophysiol 96:1646-1657. https://doi. org/10.1152/jn.00009.2006

Dotan R (2016) Children's neuromotor and muscle-functional attributes-outstanding issues. Pediatr Exerc Sci 28:202-209. https:// doi.org/10.1123/pes.2015-0248

Dotan R, Mitchell C, Cohen R et al (2012) Child-adult differences in muscle activation-a review. Pediatr Exerc Sci 24:2-21

Ertl P, Kruse A, Tilp M (2016) Detecting fatigue thresholds from electromyographic signals: a systematic review on approaches and methodologies. J Electromyogr Kinesiol Off J Int Soc Electrophysiol Kinesiol 30:216-230. https://doi.org/10.1016/j.jelek in.2016.08.002

Geneva IE, Krasteva MB, Kostianev SS (2002) Age-related changes of the somatosensory evoked potentials in healthy children. Folia Med (Plovdiv) 44:13-18

Grosset JF, Mora I, Lambertz D, Pérot C (2008) Voluntary activation of the triceps surae in prepubertal children. J Electromyogr Kinesiol Off J Int Soc Electrophysiol Kinesiol 18:455-465. https://doi. org/10.1016/j.jelekin.2006.11.002

Hatzikotoulas K, Patikas D, Ratel S et al (2014) Central and peripheral fatigability in boys and men during maximal contraction. Med Sci Sports Exerc 46:1326-1333. https://doi.org/10.1249/MSS.00000 00000000239

Henneman E, Somjen G, Carpenter DO (1965) Functional significance of cell size in spinal motoneurons. J Neurophysiol 28:560-580. https://doi.org/10.1152/jn.1965.28.3.560

Herbert RD, Gandevia SC, Allen GM (1997) Sensitivity of twitch interpolation. Muscle Nerve 20:521-523

Herda TJ, Ryan ED, Kohlmeier M et al (2018) Examination of muscle morphology and neuromuscular function in normal weight and overfat children aged 7-10 years. Scand J Med Sci Sports 28:2310-2321. https://doi.org/10.1111/sms.13256

Hermens HJ, Freriks B, Disselhorst-Klug C, Rau G (2000) Development of recommendations for SEMG sensors and sensor placement procedures. J Electromyogr Kinesiol Off J Int Soc Electrophysiol Kinesiol 10:361-374

Hu X, Rymer WZ, Suresh NL (2013) Motor unit pool organization examined via spike-triggered averaging of the surface electromyogram. J Neurophysiol 110:1205-1220. https://doi.org/10.1152/ jn.00301.2012

Kent-Braun JA, Le Blanc R (1996) Quantitation of central activation failure during maximal voluntary contractions in humans. Muscle Nerve 19:861-869. https://doi.
org/10.1002/(SICI)1097-4598(199607)19:7\%3C861 $\because$ AID-MUS8\%3E3.0.CO;2-7

Kluka V, Martin V, Vicencio SG et al (2015) Effect of muscle length on voluntary activation level in children and adults. Med Sci Sports Exerc 47:718-724. https://doi.org/10.1249/MSS.0000000000 000463

Koh TH, Eyre JA (1988) Maturation of corticospinal tracts assessed by electromagnetic stimulation of the motor cortex. Arch Dis Child 63:1347-1352

Kukulka CG, Clamann HP (1981) Comparison of the recruitment and discharge properties of motor units in human brachial biceps and adductor pollicis during isometric contractions. Brain Res 219:45-55

Lauffer H, Wenzel D (1986) Maturation of central somatosensory conduction time in infancy and childhood. Neuropediatrics 17:72-74. https://doi.org/10.1055/s-2008-1052504

Lexell J, Sjöström M, Nordlund AS, Taylor CC (1992) Growth and development of human muscle: a quantitative morphological study of whole vastus lateralis from childhood to adult age. Muscle Nerve 15:404-409. https://doi.org/10.1002/mus.880150323

Long D, Dotan R, Pitt B et al (2017) The electromyographic threshold in girls and women. Pediatr Exerc Sci 29:84-93. https://doi. org/10.1123/pes.2016-0056

Marginson V, Eston R (2001) The relationship between torque and joint angle during knee extension in boys and men. J Sports Sci 19:875-880. https://doi.org/10.1080/026404101753113822

Martin V, Kluka V, Garcia Vicencio S et al (2015) Children have a reduced maximal voluntary activation level of the adductor pollicis muscle compared to adults. Eur J Appl Physiol 115:14851491. https://doi.org/10.1007/s00421-015-3132-x

Merletti R, Holobar A, Farina D (2008) Analysis of motor units with high-density surface electromyography. J Electromyogr Kinesiol Off J Int Soc Electrophysiol Kinesiol 18:879-890. https://doi. org/10.1016/j.jelekin.2008.09.002

Merton PA (1954) Voluntary strength and fatigue. J Physiol 123:553-564

Miller JD, Herda TJ, Trevino MA et al (2017) Age-related differences in twitch properties and muscle activation of the first dorsal interosseous. Clin Neurophysiol Off J Int Fed Clin Neurophysiol 128:925-934. https://doi.org/10.1016/j.clinph.2017.03.032

Miller JD, Sterczala AJ, Trevino MA, Herda TJ (2018) Examination of muscle composition and motor unit behavior of the first dorsal interosseous of normal and overweight children. J Neurophysiol 119:1902-1911. https://doi.org/10.1152/jn.00675.2017

Miller JD, Sterczala AJ, Trevino MA et al (2019) Motor unit action potential amplitudes and firing rates during repetitive muscle actions of the first dorsal interosseous in children and adults. Eur J Appl Physiol. https://doi.org/10.1007/s00421-019-04090-0

Mirwald RL, Baxter-Jones ADG, Bailey DA, Beunen GP (2002) An assessment of maturity from anthropometric measurements. Med Sci Sports Exerc 34:689-694

Müller K, Hömberg V, Lenard HG (1991) Magnetic stimulation of motor cortex and nerve roots in children. Maturation of corticomotoneuronal projections. Electroencephalogr Clin Neurophysiol $81: 63-70$

Nawab SH, Chang S-S, De Luca CJ (2010) High-yield decomposition of surface EMG signals. Clin Neurophysiol Off J Int Fed Clin Neurophysiol 121:1602-1615. https://doi.org/10.1016/j.clinp h.2009.11.092

O'Brien TD, Reeves ND, Baltzopoulos V et al (2009) The effects of agonist and antagonist muscle activation on the knee extension moment-angle relationship in adults and children. Eur J Appl Physiol 106:849-856. https://doi.org/10.1007/s00421-009-1088-4

O'Brien TD, Reeves ND, Baltzopoulos V et al (2010) In vivo measurements of muscle specific tension in adults and children. Exp Physiol 95:202-210. https://doi.org/10.1113/expphysiol.2009.048967 
O'Brien TD, Reeves ND, Baltzopoulos V et al (2012) Commentary on child-adult differences in muscle activation-a review. Pediatr Exerc Sci 24:22-25

Piponnier E, Martin V, Bontemps B et al (2018) Child-adult differences in neuromuscular fatigue are muscle-dependent. J Appl Physiol (1985). https://doi.org/10.1152/japplphysiol.00244.2018

Pitt B, Dotan R, Millar J et al (2015) The electromyographic threshold in boys and men. Eur J Appl Physiol 115:1273-1281. https://doi. org/10.1007/s00421-015-3100-5

Pope ZK, Hester GM, Benik FM, DeFreitas JM (2016) Action potential amplitude as a noninvasive indicator of motor unit-specific hypertrophy. J Neurophysiol 115:2608-2614. https://doi.org/10.1152/ jn.00039.2016

Ratel S, Kluka V, Vicencio SG et al (2015) Insights into the mechanisms of neuromuscular fatigue in boys and men. Med Sci Sports Exerc 47:2319-2328. https://doi.org/10.1249/MSS.0000000000 000697

Sterczala AJ, Herda TJ, Miller JD et al (2017) Age-related differences in the motor unit action potential size in relation to recruitment threshold. Clin Physiol Funct Imaging. https://doi.org/10.1111/ cpf. 12453

Stock MS, Beck TW, Defreitas JM (2012) Effects of fatigue on motor unit firing rate versus recruitment threshold relationships. Muscle Nerve 45:100-109. https://doi.org/10.1002/mus.22266

Streckis V, Skurvydas A, Ratkevicius A (2007) Children are more susceptible to central fatigue than adults. Muscle Nerve 36:357-363. https://doi.org/10.1002/mus.20816
Suter E, Herzog W (2001) Effect of number of stimuli and timing of twitch application on variability in interpolated twitch torque. J Appl Physiol (1985) 90:1036-1040. https://doi.org/10.1152/jappl .2001.90.3.1036

Tanner JM, Whitehouse RH (1976) Clinical longitudinal standards for height, weight, height velocity, weight velocity, and stages of puberty. Arch Dis Child 51:170-179

Tomko PM, Colquhoun RJ, Magrini MA et al (2018) Global electromyographic signal characteristics depend on maximal isometric contraction method in the knee extensors. J Electromyogr Kinesiol 42:111-116. https://doi.org/10.1016/j.jelekin.2018.07.002

Trevino MA, Herda TJ, Fry AC et al (2016) Influence of the contractile properties of muscle on motor unit firing rates during a moderateintensity contraction in vivo. J Neurophysiol 116:552-562. https ://doi.org/10.1152/jn.01021.2015

Trevino MA, Sterczala AJ, Miller JD et al (2018) Sex-related differences in muscle size explained by amplitudes of higher-threshold motor unit action potentials and muscle fibre typing. Acta Physiol Oxf Engl. https://doi.org/10.1111/apha.13151

Publisher's Note Springer Nature remains neutral with regard to jurisdictional claims in published maps and institutional affiliations. 